\title{
Connectivity of the Public Realm: The Case of Bahrain Fort and King Faisal Corniche in Bahrain
}

Fatima Shubbar $^{1}$, Raffaello Furlan ${ }^{2 *}$

\begin{abstract}
${ }^{1}$ Architect, B.Sc. Arch - University of Bahrain (Kingdom of Bahrain) Master in Urban Planning and Design (MUPD) Candidate, College of Engineering, Department of Architecture and Urban Planning, Qatar University Qatar

${ }^{2}$ Architect, PhD - Griffith University (Australia), BArch, MArch - IUAV (Italy) Assistant Professor, College of Engineering, Department of
\end{abstract} Architecture and Urban Planning, Qatar University Qatar

DOI: $10.36348 /$ SJCE.2019.v03i05.004

| Received: 09.09.2019| Accepted: 17.09.2019| Published: 29.09.2019

*Corresponding author: Raffaello Furlan

\section{Abstract}

In the past few decades, cities and/or urban settlements have been experiencing growing population and environmental degradation. Environmental trends, such as biodiversity loss and global warming are increasing rapidly, as a result of the ecological footprints of cities. Gulf cities, for example, have been rapidly developed since the discovery of oil and under the influence of globalization as they transition from traditional settlements into modern metropolitan cities. With this fast modernization, green and agricultural spaces have been reduced and/or replaced by built-up areas and buildings, alien to the multilayered historical built form, changing the built environment of cities and causing environmental, social, and economic problems. Consequently, the planning of parks and open spaces have been neglected within the formulation of modern master planning of cities, resulting in the formation of areas mostly scattered in empty lots. Parks and open spaces, often disconnected from the existing built form of cities, do not fit into the neighborhood's scale. Simply planned to fulfill the human need for recreation, these scattered open spaces lack connectivity between them and have weak accessibility/connectivity to their neighborhoods. Namely, this research study (1) investigates the accessibility and connectivity of Bahrain Fort and King Faisal Corniche in Bahrain with the surrounding neighborhoods, (2) reveals the factors affecting the connectivity of the two significant sites and accordingly (3) proposes the strategies to enhance it. Keywords: Green Urbanism, Green Infrastructure, Bahrain Fort, King Faisal Corniche, Connectivity, Accessibility.

Copyright @ 2019: This is an open-access article distributed under the terms of the Creative Commons Attribution license which permits unrestricted use, distribution, and reproduction in any medium for non-commercial use (NonCommercial, or CC-BY-NC) provided the original author and source are credited.

\section{INTRODUCTION}

Currently, cities are facing economic, environmental, and social challenges, which are a result of rapid modernization, urban sprawl, and industrial revolution; cities in the Gulf region have been dramatically affected by these challenges. Starting with the discovery of oil in the early 1930s followed by the globalization trend which begun in the 1970s, small traditional towns were transformed into ultra-modern cityscapes within one short generation [1-3]. Consequently, cities had to focus on modernization and neglected many important aspects, particularly, the availability and accessibility of green areas and open spaces. Modern fashionable structures were built on the expenses of many green and agricultural areas, severely damaging and destroying them. Also, the concept of open spaces was rarely introduced within the planning strategy, except for few major projects, and neighborhood parks[4,5].
The Kingdom of Bahrain is one of these places that have witnessed an intense shift in its urban form and morphology. Since the 1970s, there were initiatives to preserve the existing green and agricultural areas and develop a master plan with a greenbelt[6]. Although it includes several parks and open spaces today, they are still considered too few and have weak connections between them. They are mainly distributed randomly in the master plan without studying their relation to and impact on the city and the environment, including people's needs, the provision of public amenities, and accessibility and connectivity to the surrounding parks and open spaces. Also, a huge part of the sea has been reclaimed mainly for real-estate investments with relatively limited access to the public.

For this reason, this research focuses on Bahrain Fort and King Faisal Corniche as the main study area. The two sites are important points of attraction located in Manama city, the capital of the Kingdom of Bahrain (Figures 1 and 2). Bahrain Fort 
was listed as a UNESCO world heritage site in 2005[7], and was transformed into a tourist attraction. The protection and management of the archeological site, along with development and revitalization, enabled the transformation. A museum was created to exhibit the discoveries made at the site and a café offers visitors a charming view of the beach and the fort, and walkways connect the museum with the fort, and they are used by visitors and locals for sport and leisure activity.

On the other hand, King Faisal Corniche, is located approximately 5 kilometres away from Bahrain fort, and is considered one of the major sea fronts in Bahrain. Al-Nabi[6] mentioned that the corniche was constructed during the mid-1980s on a reclaimed land to the east and west of old Manama harbour. The corniche is considered an attractive area that is crowded with visitors of all types, as it offers walkways with a sea view, green spaces, a children's play area, and other public amenities. The corniche also overlooks the important landmark of Bahrain Financial Harbour $(\mathrm{BFH})$, and it is also opposite old Manama city, to which it is connected with Manama Souq through a pedestrian bridge.

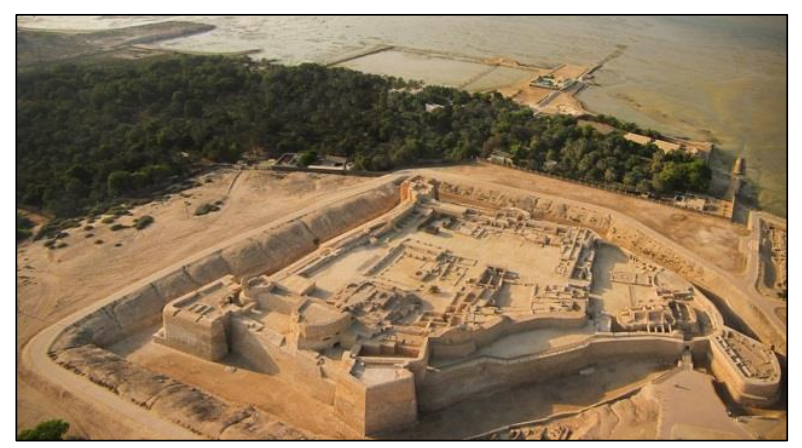

Fig-1: Bahrain Fort. Source: Hussam Qasem

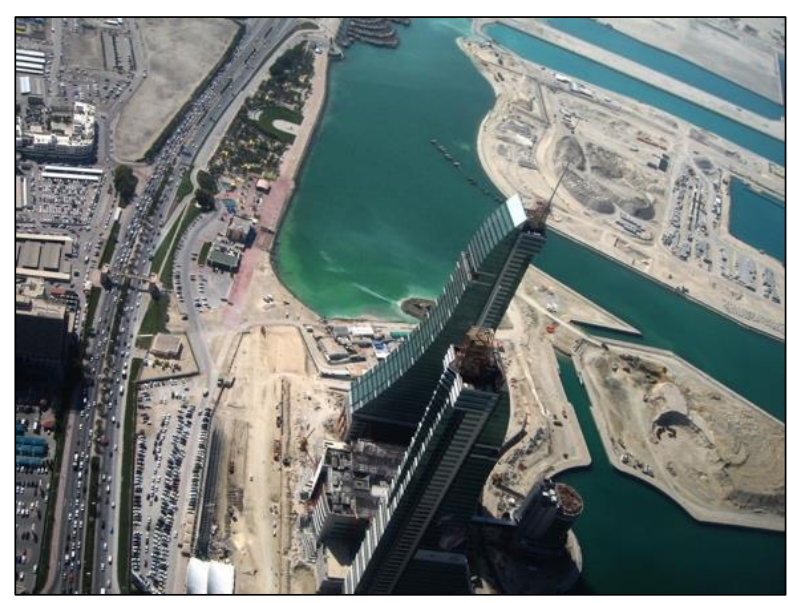

Fig-2: King Faisal Corniche. Source: wegenforum.nl

The aim of this research study is to investigate the factors affecting the connectivity of the study area in relation to the surrounding nearby parks and open spaces, landmarks, and shopping malls. The research adopts two qualitative methods of data collection, which are a review of relevant literature, followed by site analysis and observations through several site visits, pictures, and maps. Based on the results and findings, the research proposes strategies to develop the site and its connectivity with the surroundings and make it accessible to the public to improve livability and the public realm.

\section{LITERATURE REVIEW Green Urbanism}

Green Urbanism concerns the central urban and environmental dimensions and it has an important role in shaping urban areas positively so they offer more sustainable places, communities, and lifestyles. It also proposes that traditional approach to the concept of urbanism and our views of cities, towns, and communities are incomplete because they lack the integration of ecology to produce ways of life and settlements that are ecologically responsible. The vision of green urbanism includes several important design qualities and characteristics that should be included in cities: to facilitate sustainability; to live within their ecological limits and reduce their ecological footprint; to enhance livability; to achieve local and regional selfsufficiency; to achieve circular metabolism; and to provide cities that are designed to be analogous to nature [8-10].

In European cities, the primary objective of green urbanism is to endorse sustainability through legislation and directives. Specific directives require strong attention to environmental protection and conservation. National sustainability strategies were prepared, in addition to national-level action plans and standards. For example; the document Green Paper on the Urban Environment was published in 1990 and is considered as a milestone. The paper called for cohesive and comprehensive methods to planning and affirmed the need to view cities as a crucial part of solving global environmental problems [11, 8, 12, 13].

In the same way, the European Sustainable Communities report calls for the same approach; however, it goes further in arguing for an ecosystem view of cities, which affect the environment in which they are located and they are the home of plants and animals. Therefore, they should be viewed as a complex, interconnected and dynamic system. Urban sustainability needs to solve the problems experienced within cities themselves and the problems caused by them[8].

In addition to the overall concept of urban sustainability, the report identifies four principles: urban management, policy integration, ecosystems thinking, partnership and cooperation. Furthermore, sustainability requires management. Sustainable management is a learning process that has eight key elements, which are learning by doing; sharing experiences; professional education, training, partnerships, networks, community participation and 
innovative education mechanisms [8, 14, 15, 16]. Figure 3 shows the principles of green urbanism and their interconnections.

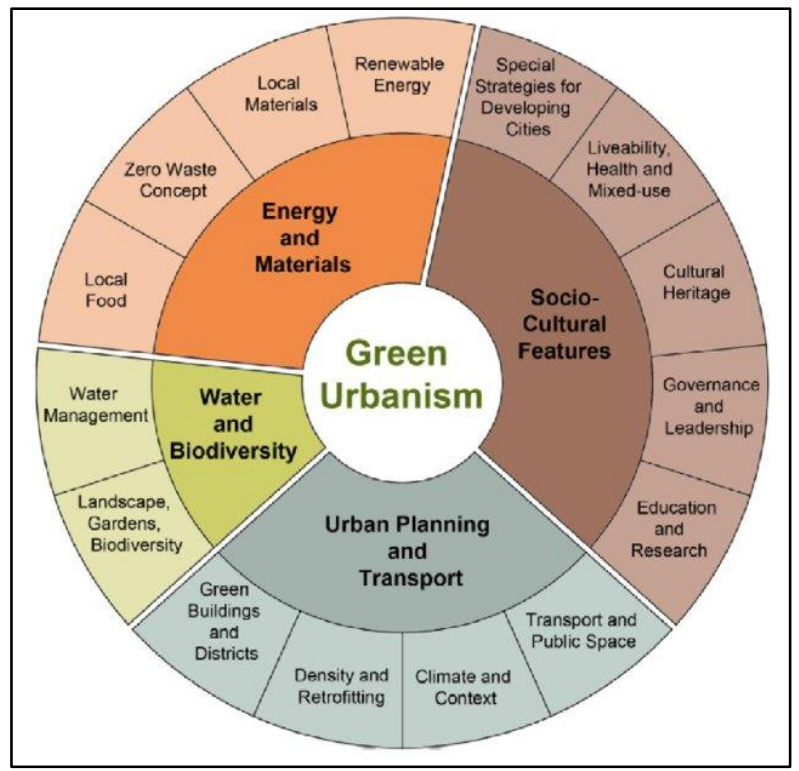

Fig-3: Principles of green urbanism and their interconnections. Source: Lehmann, 2010.

\section{Parks and Open Spaces}

Parks or green open spaces emerged historically from green lands around cities that were used for agricultural purposes. Later these lands were developed as a recreation and social gathering spaces. Gradually, the usage of parks has increased and expanded to become a source contributing to the health and fitness of its users, thus users had new demands which affected the planning and design of parks. During the nineteenth century, the rapid industrialization and mass migration to urban areas in Europe and North America generated crowded urban spaces and affected the quality of urban life. As a result, large city parks began to appear all over European and North American cities. It was noticed by planners and landscape designers that these parks gave people physical and mental relief from the unhealthy environment caused by industrialization [17]. In addition to enhancing and beautifying the urban environment, urban parks constituted important structural components in shaping the urban form $[17,18,12,20]$.

Urban parks were defined by Maulan [21] as plots located in urban areas and set aside for the use of the public, and they include recreational, aesthetic appreciation, cultural and educational aspects. The usage of parks is not restricted to a specific class of people nor a specific time, is it rather used by people of different ages, genders and backgrounds and during all times of the day, week, and year. To create green spaces that host the needs of people for fresh air and recreation, planners and landscape designers need to work with policy makers and engage the community to participate with their governments. Consequently, the quality of life in cities will be improved through offering recreational spaces that are aesthetically pleasing [17, 22-25].

The advantage of having trees in urban areas is that it reduces temperature through the creation of shaded areas and reduces air pollution through purifying the air. The purification of air is achived through absorbing carbon dioxide and emitting oxygen. Also, the attractiveness of a city is increased due to the aesthetic and recreational values of public parks. They also transform a city into a tourist destination which includes economic benefits. Exposure to the natural environment also reduces stress levels rapidly and therefore enhances the quality of life $[17,14,26]$.

There is variety of urban parks in urban areas that serves leisure needs and support revitalization goals. They also enhance the sense of culture, liveliness, and identity of an area. Therefore, pursuing creative solutions to provide open space and recreational facilities in these areas is important. Moreover, the types of urban parks vary from a small park located within a pedestrian oriented walkway to a large open space constituted of different amenities and able to host large community gatherings. Accordingly, the types of urban parks can be divided into three categories; mini; neighborhood; and community parks $[17,26,28,10]$.

Mini parks are located in a neighborhood and have an area of less than 400 square metres. The main purpose of this type of park is to provide recreational opportunities for children. In contrast, neighborhood parks which have an area of 20,000 square metres serve the recreational needs of adults and children aged 6 to 15 years. On the other hand, community parks serve different needs of youth and adults. These parks comprise active and passive recreation and facilities including sports fields, playgrounds, picnic areas, restrooms and public amenities and off-street parking. This type of parks usually has an area ranging between 40,000 to 200,000 square meters $[17,29,9,22]$.

The attractiveness and usage of parks is influenced by several features such as access to different facilities in the park that supports the recreational activities. The availability of park amenities is very important for the usage of parks regardless of the age of users. These include barbecues, seating, water fountains, picnic tables, and restrooms. In addition to those amenities, the presence of shade and the appropriate placement of shading devices is another attribute encouraging the uses of parks. Additional features contributing to the positive usage of parks were the inclusion of aesthetic features such as greenery and water features, good air quality, soothing odors, sounds of nature, and peace and quiet in the park. Moreover, the social environment is another attribute that encourages park usage through organized festivals and 
celebrations, as these activities combine people of different backgrounds together in one place [30].

However, various issues discourage the usage of parks including poor maintenance and cleanliness, uneven ground or playing surfaces, scarcity of grass and inadequate sidewalks. Moreover, the presence of undesired users in the parks such as drug dealers and homeless persons seriously affects the usage of parks. Therefore, maintaining safety in parks can be done by providing good lighting, a law-enforcement presence and security surveillance. Additionally, an important factor affecting the usage of parks is related to the accessibility and closeness of parks. The existence of local parks within walking distances from residential, commercial, and institutional areas was positive and increased the probability of park usage [30]. Figure 4 shows a diagram explaining the tangible and intangible attributes that contributes to making a park a good place.

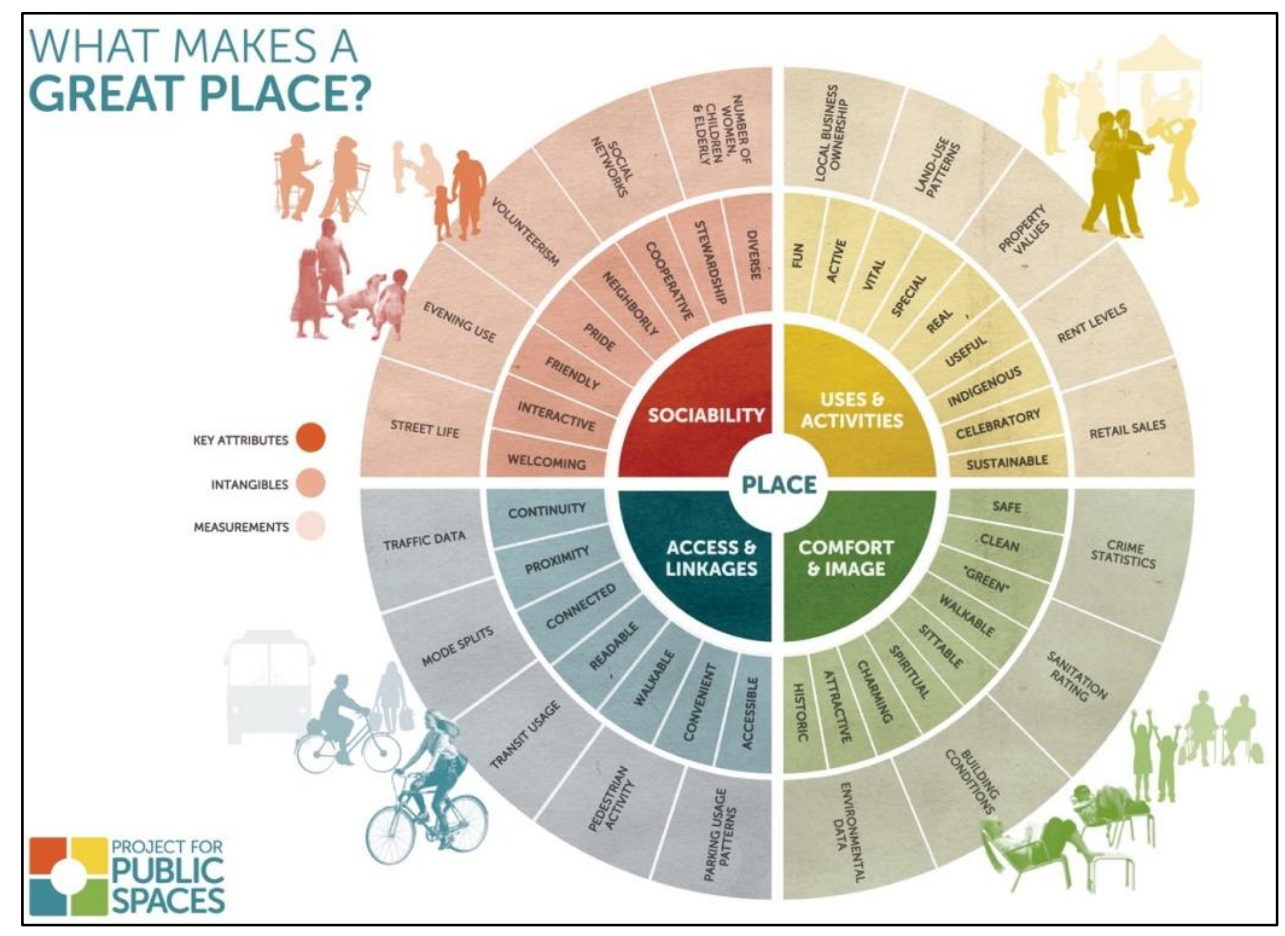

Fig-4: Place Diagram. Source: PPS

\section{Connectivity}

Connectivity or permeability is the degree to which the movement of people or vehicles movement is restricted in different directions by the urban form. It is referred to the availability of connection leading into and moving out of a space. Transportation systems are linked with connectivity; their characteristics can either reduce or increase the traveling potential to different urban areas. For good connectivity, pedestrians need easy access to urban areas and a decreased need for using cars. Connectivity is enhanced by creating short and easy trips that are pleasant for walking instead of driving [31].

Connectivity is classified by three categories, which are structural connectivity, potential connectivity, and functional or actual connectivity. All of these types can be measured with metric units and indicators with different complexity ranges, and they are considered useful in the assessment of urban green infrastructures [32]. Potential connectivity is linked to the transportation network. It refers to how direct and dense the links are in a network. A transportation network is considered highly permeable if it has many short links and several intersections with fewer dead ends. Permeability reduces the travel distances to different urban facilities and provides a variety of road options, which allow more direct travel between destinations and therefore makes the transportation system more accessible and resilient (Figure 5) [31]. 


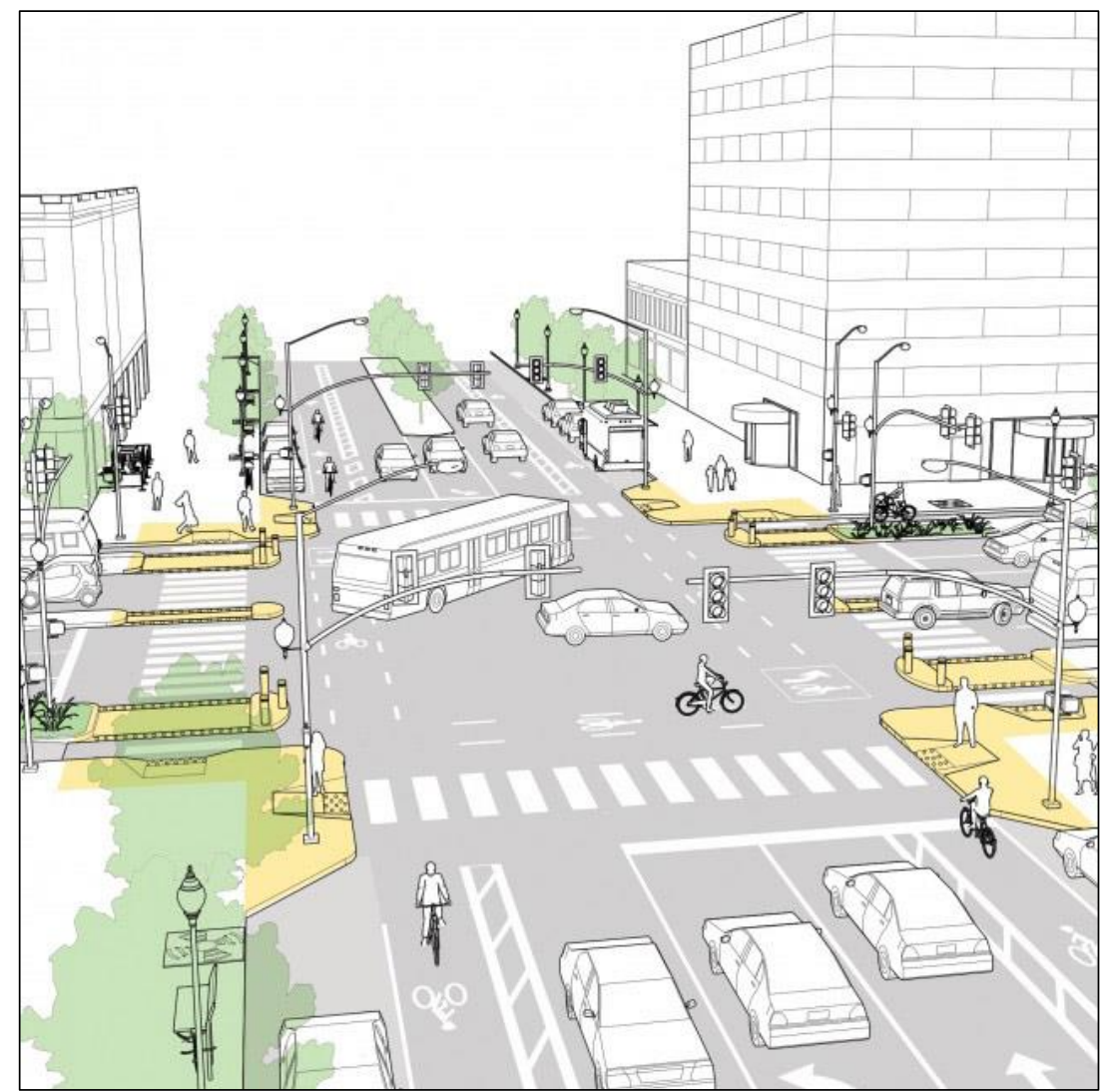

Fig-5: Connectivity image showing different types of transportation systems. Source: nacto.org

In terms of connectivity, the focus is more on active transportation which includes walking or cycling. Determining active transportation is based on several variables including street connectivity, exposure to traffic, availability of sidewalks and restrained crossings, the density and speed of traffic, and the number of roads crossed [32]. Walkability and 'bikeability' can be increased by enhancing streets and pedestrian pathways, providing bicycle lanes, adding street furniture, planting trees, installing public art, and providing desirable streets. Good streets are considered desirable if they are characterized by the following: good quality and condition, places to sit, constructed on a human scale, signage for destination, visual complexity, detailed façade, diversity of use, focal point, safe and permeable [8].

\section{Public Urban Green Spaces in Bahrain}

The Kingdom of Bahrain is a small country that is strategically located in the Arabian Gulf with an area of about 700 square kilometres. It is an archipelago consisting of thirty-six islands surrounding a main island (Figure 6). Manama is the capital city situated to the north coast of the main island overlooking the Gulf. Currently, most of the commercial and governmental activities are located within the capital [33]. Because of the growing population and urbanization, as well as new institutions, companies, and housing units developing outside Manama in different cities, automobiles invaded the Manama. This has resulted in a society strongly dependent on car travel instead of walking and using public transportation.

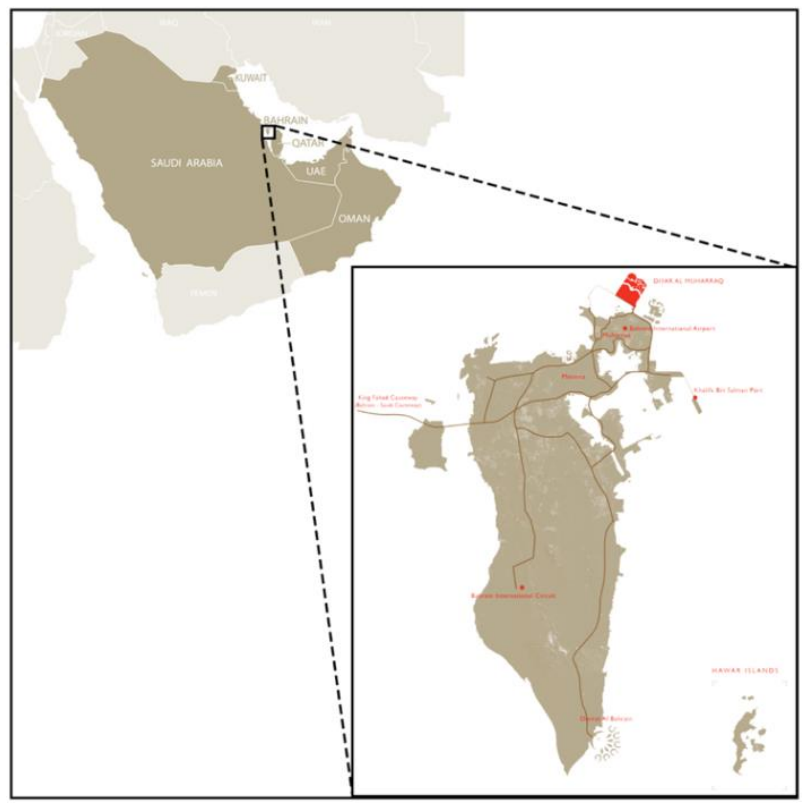

Fig-6: Map of Bahrain. Source: Authors

A land use study has been conducted in different areas of Bahrain. The study indicates that the newly developed areas, such as Juffair and Seef, needed less green space and fewer parks because of the huge plot of areas it incorporates, the lower population density, and the fact that some buildings had their own 
gardens. In contrast, highly dense old areas, such as Manama and Muharraq, accommodated high population density. These areas were composed of small plots and fewer natural areas, so they needed more green space[17].

The estimated population in Bahrain has increased dramatically from 650,604 in 2001 to $1,314,562$ in 2014 [17]. As seen in figure 3, the area of land has increased as a result of land reclamation of 757.9 square kilometres in 2009 to 765.3 square kilometres in 2015 [6]. The data retrieved from Bahrain Open Data Portal estimated that the area of green parks in Manama is 344.8 acres, and the total population in Manama is 497,000 [34]. Consequently, each person's share of park is equal to 2.77 square metres. As per the study of land-use maps of Bahrain, the number and distribution of parks is not sufficient in relation to the population. The 2.77 square metres per person share of the park is considered less than the international standards which is 9 square metres per person according to the World Health Organization[17].

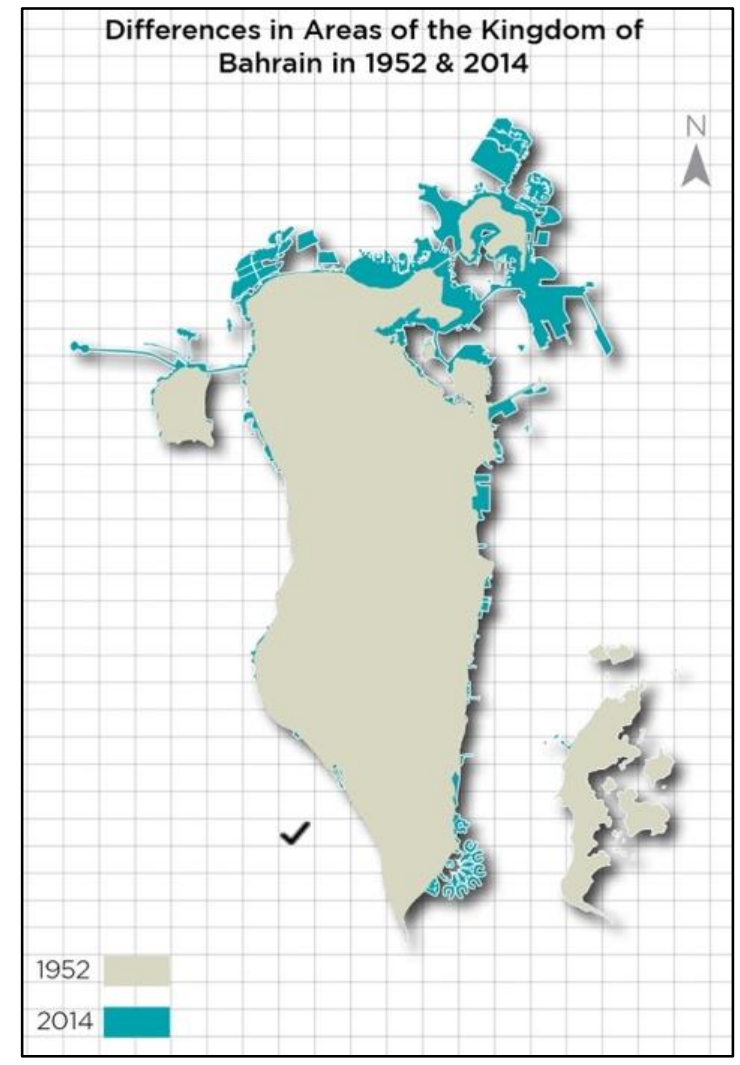

Fig-7: Comparison of Bahrain's map between 1952 and 2014

$$
\text { Source:[34] }
$$

In 2008 the government of Bahrain developed a national vision for 2030. This plan tackles issues of natural resources, inadequate housing, and lack of zoning. In addition, the plan focuses on the problem of weak transportation infrastructure, insufficient public open space and the need for improved education and comprehensive employment (Figure 8) [35]. Furthermore, in conjunction with this vision the principles of Bahrain National Strategic Planning were developed, and the overall objectives were to provide a safe and satisfying environment; to attain sustainable quality growth, to provide adequate infrastructure, to enhance the performance and efficiency of the government, to provide appropriate and accessible social services, and to ensure sustainable development of strategic resources[36].

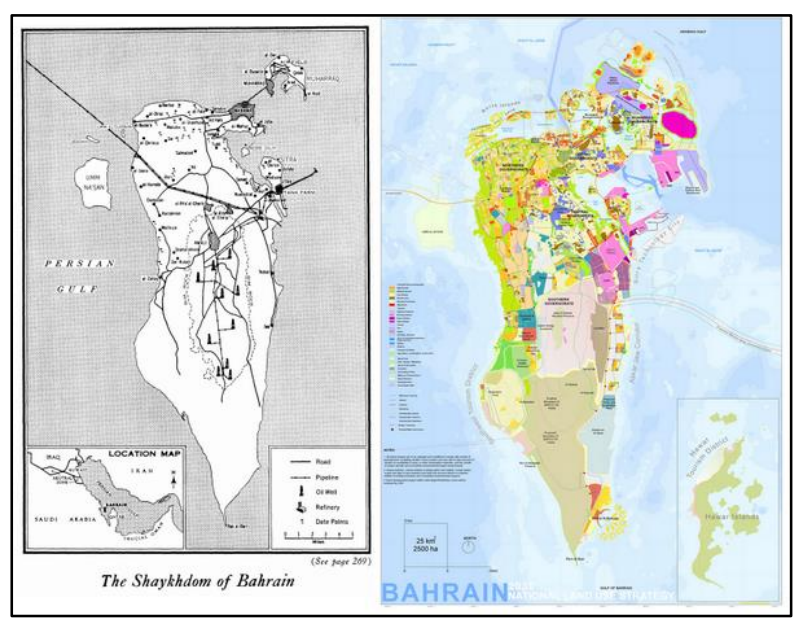

Fig-8: Bahrain's map in 1955 compared to its Vision 2030. Source: Twitter.com

\section{THE RESEARCH DESIGN}

The literature review provided an overview of the concept and vision of green urbanism and the principles of urban sustainability both of which emphasises the environmental issues and the need to reduce the city's ecological footprints. Also, it highlighted the history of the existence of parks and open spaces, their definition and role in the city, their types and the attributes affecting the usage of parks. The description of connectivity and the characteristics that increase walkability and bikeability were reviewed.

Moreover, the topics of public urban green spaces in Bahrain, the total area of the site in relation to the number of parks, the share of public parks available in Bahrain for each person compared to national standards, and the objective of Bahrain National Vision 2030 were reviewed.

The research study highlights Bahrain Fort and King Faisal Corniche in Manama as the area to be investigated. The selection of these two locations is due to their importance as well-known landmarks that attract tourists. They are also located around other major landmarks that present an interesting opportunity for connectivity, such as malls, community parks, agricultural lands, Manama Souk, and commercial and office areas.

\section{DATA COLLECTION}

The objective of this study is to explore the aspects affecting the accessibility and connectivity of these two locations in relation to their context and 
propose strategies that further enhance the area for the public. The methods adopted in this research study are qualitative. Primary data was collected through site analysis (site visits, site observation, photographs and maps of the locations and surroundings)[37-39].

The findings and conclusions appropriately answer the research questions of this paper: (1) how should the accessibility and connectivity of "Bahrain Fort" and "King Faisal Corniche" be measured? (2) How can these two locations be connected with their surroundings?

\section{DATA ANALYSIS}

After reviewing the literature, which provided a conceptual framework for the research study, and after collecting the required data, in turn analyzed, criteria were developed to further guide the analysis of data and process the findings:

- Determining the location of the two areas;

- Classifying the surrounding context according to the land use;

- Identifying the existing features and problems of the sites and surroundings;

- Developing a strategy to enhance the accessibility and connectivity of the analized sites.

Findings were summarized and listed, along with discussion, followed by concluding remarks and implications for practice and further advancement of the research. The diagram below displays the methodological framework adopted in this research study.

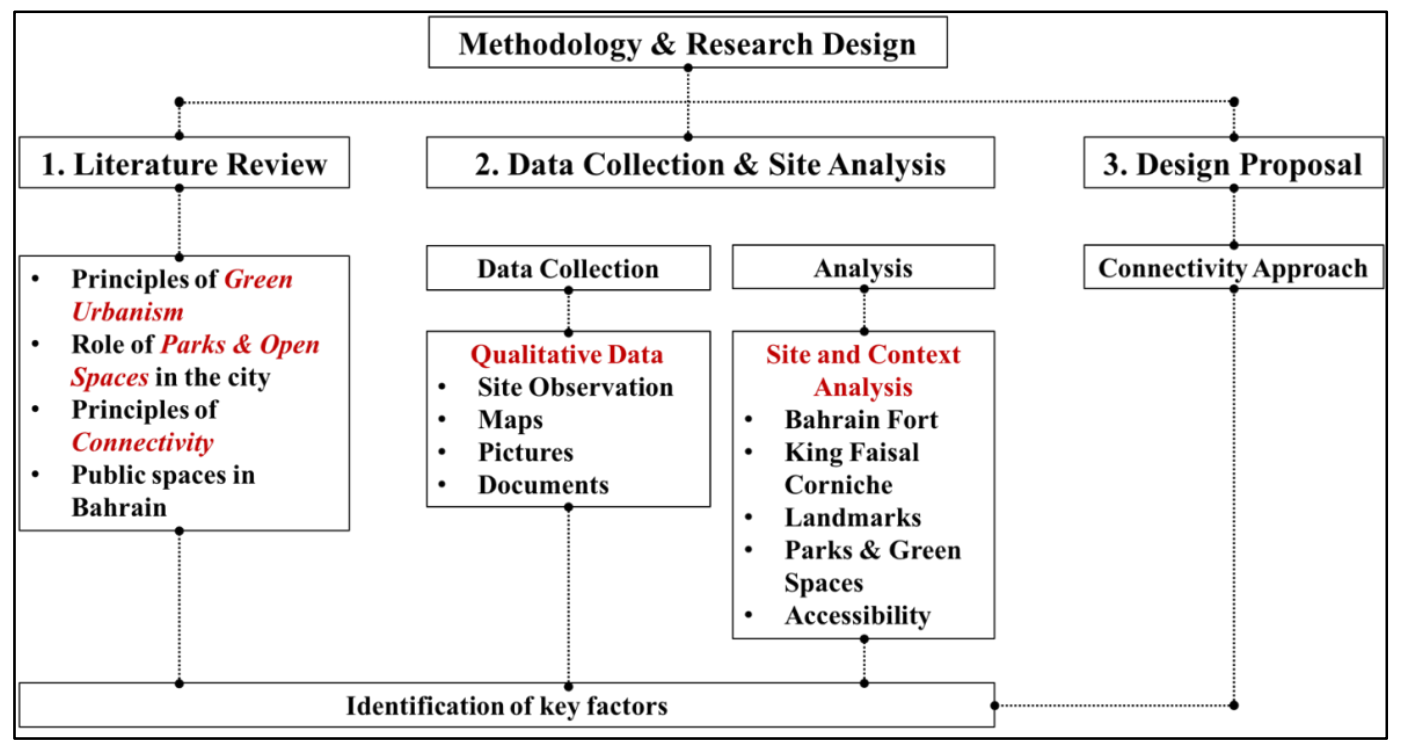

Fig-9: Summary of the methodological framework. Source: Authors

\section{FINDINGS}

After being named as a world heritage site, the Bahrain Authority for Culture and Antiquities (BACA) added some features to the Bahrain Fort national heritage site to make it more attractive, in addition to preserving the site itself. A museum has been constructed close to the site which has a view of the Karbabad coast, and a walkway has been created around the fort and connected to the museum (Figure 10). The museum displays heritage artifacts found during excavations. It also has a small café with a veranda looking over the sea (Figure 11). During cultural events and festivals such as the Spring of Culture, which is held annually and organized by BACA, the museum hosts activities such as a light show, musical events, galleries, and poetry events (Figure 12).

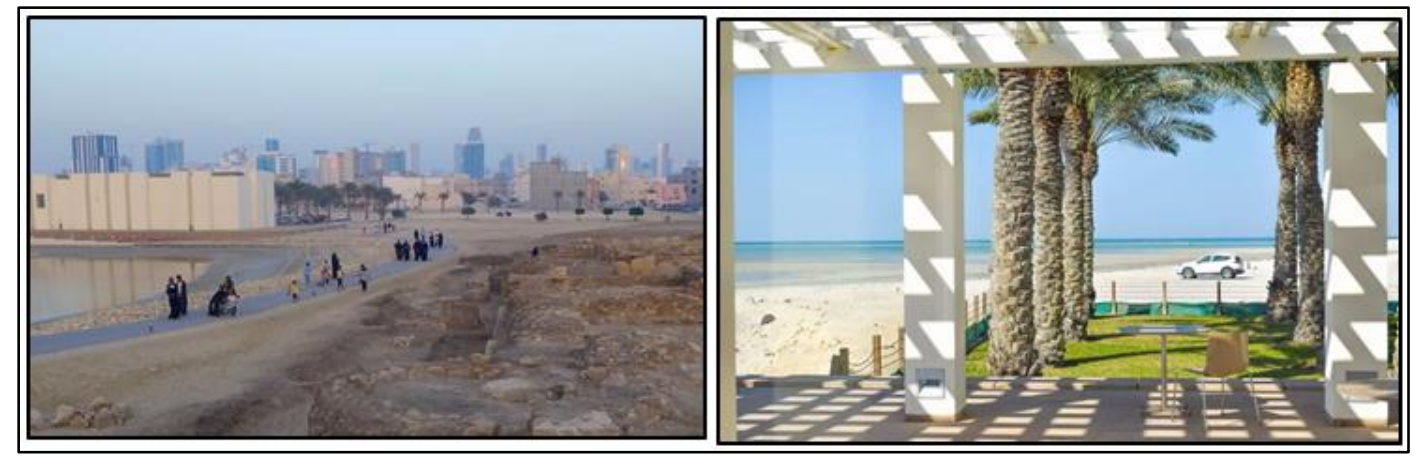

Fig-10: The walkway linking the museum with the fort. Source: Inserro, J. Figure 11: The museum veranda. Source: Kuruvilla, J. 


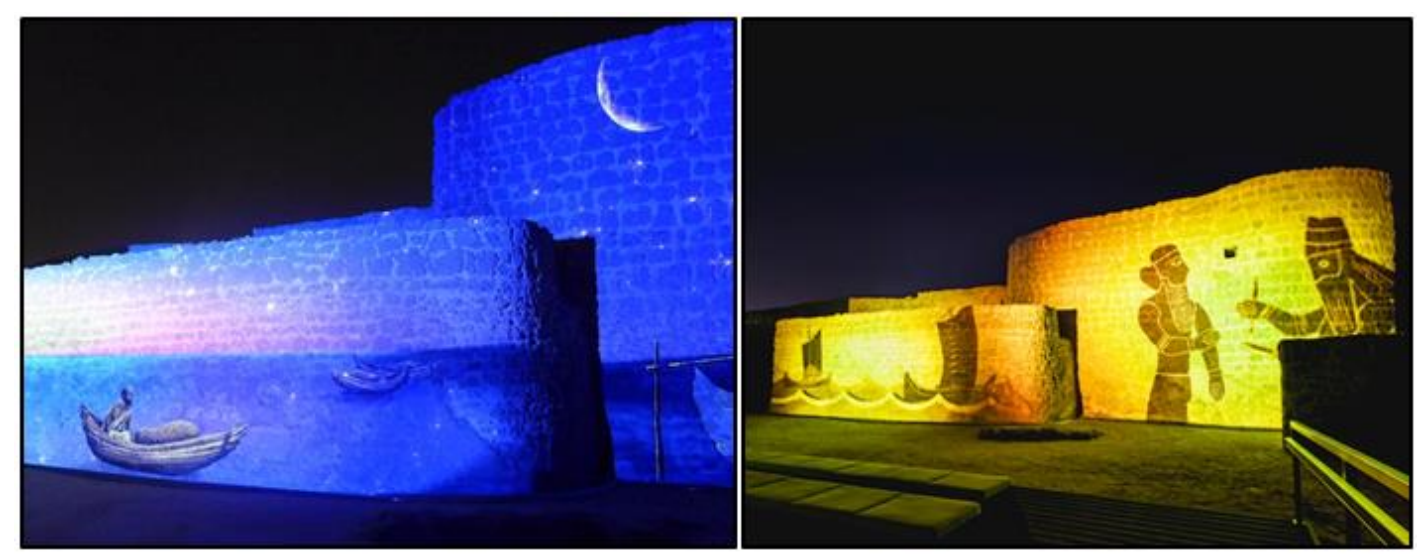

Fig-12: A carbon-neutral AV show at Bahrain Fort. Source: Inserro, J.

The location is accessed through secondary roads with week access. The walkway is used by many people almost at all times, and it is crowded with visitors during the winter season. The walkway is accessible to the public and has a route leading inside the fort and around it. However, the walkway stops within the fort and its museum. There is no connection between them and the Karbabad coast.

Karbabad coast is open to the public who use it for walking or recreational purposes. More than a year ago, the coast has been infused with small home businesses, which enriched the coast and attracted more people to it. These were mainly booths offering food and beverages, as well as portable children's play areas. Although the cost was accessible, there were no public amenities offered, such as a sitting area, lighting, trash bins, and public toilets. As a result, the coast remained uncleaned and filled with dirt.

Small neighborhood parks surround Bahrain Fort and include Al Seef park, Karbabad Garden, Maqsha'a Garden, and Jidhafs Garden. Also, there is a huge green area used for agriculture that includes $\mathrm{Al}$ Nakheel road, which links Karbabad, Maqsha'a, and Budaya villages. The existence of this area is interesting because the majority of green agricultural areas have vanished over time (Figure 13).

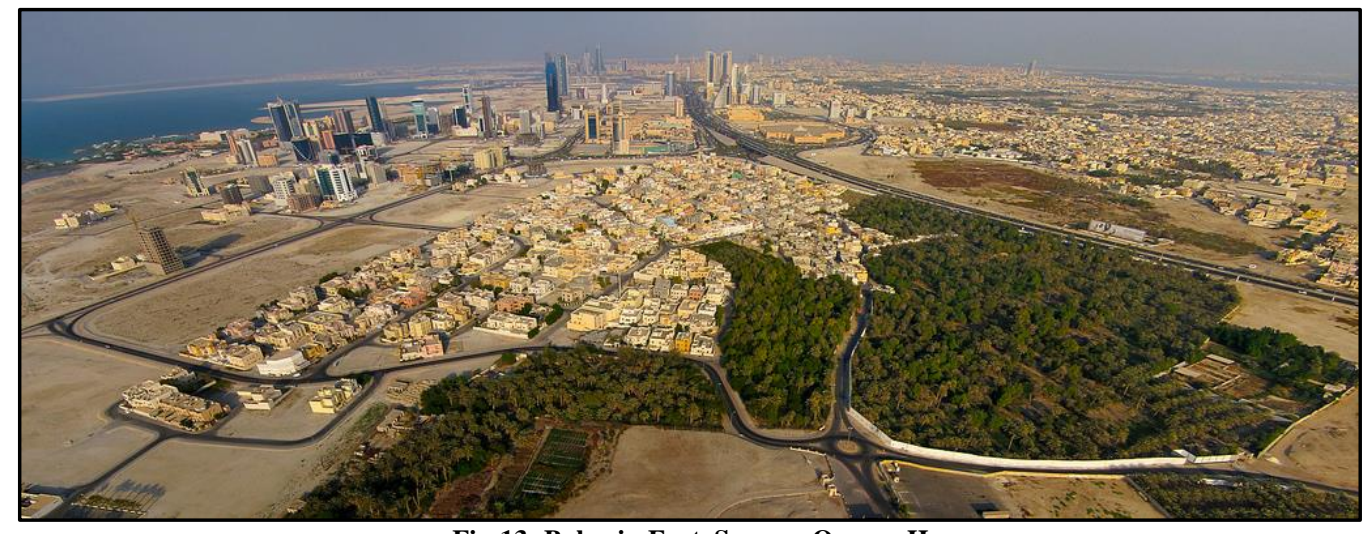

Fig-13: Bahrain Fort. Source: Qasem, H

The area next to Karbabad is the Al Seef area, which is a commercial district incorporating high-rise office and apartment buildings and hotels, as well as several major shopping malls that dominate the area. The existing shopping malls are Al Seef mall, Al Aali shopping complex, and City Center Bahrain mall. In addition to these shopping malls, there are several shopping areas such as Seef Corner and Aali Boulevard with interesting landscaping along with fine dining restaurants and cafes with an access to Al Aali shopping complex. The access to these attractions is mainly through King Faisal Highway or Shaikh Khalifa Bin Salman Highway or from Avenue 40 or Al Nakheel Highway.
Close to City Center Bahrain, there are two new developments which are Reef Island and Water Garden City. Both developments are constructed on reclaimed land. The access to these developments is mainly through a bridge from King Faisal Highway or from the road leading to City Center Bahrain. Reef Island is basically residential and comprises high-rise developments. The access to this area is restricted to its residents. However, there is a commercial area inside that is accessible to the public. This commercial area has a view to the sea and consists of restaurant and cafes, along with a small garden. The Water Garden City comprises commercial areas and cafes. 
Overlooking the island is King Faisal Corniche. The area is located along the major roads and is accessible by the King Faisal Highway or from Bahrain Bay through road 4607 (Figure 14). The corniche is mostly crowded during the middle of the day until night. The users of the space are local Bahrainis, Gulf residents, Arab residents, and expatriates. The site contains a park, a walkway, a children's playground and few restaurants and cafés.
The corniche lacks adequate public amenities, and due to the huge population, the site as not clean. Also, the corniche is connected with old Manama city through an elevated pedestrian bridge, which presents an opportunity to visit Manama Souq. The corniche also has another important feature, which is its location next to Bahrain Financial Harbor (BFH), is a skyscraper consisting of major commercial developments that dominate the area along with Bahrain World Trade Center (WTC) (Figure 15).

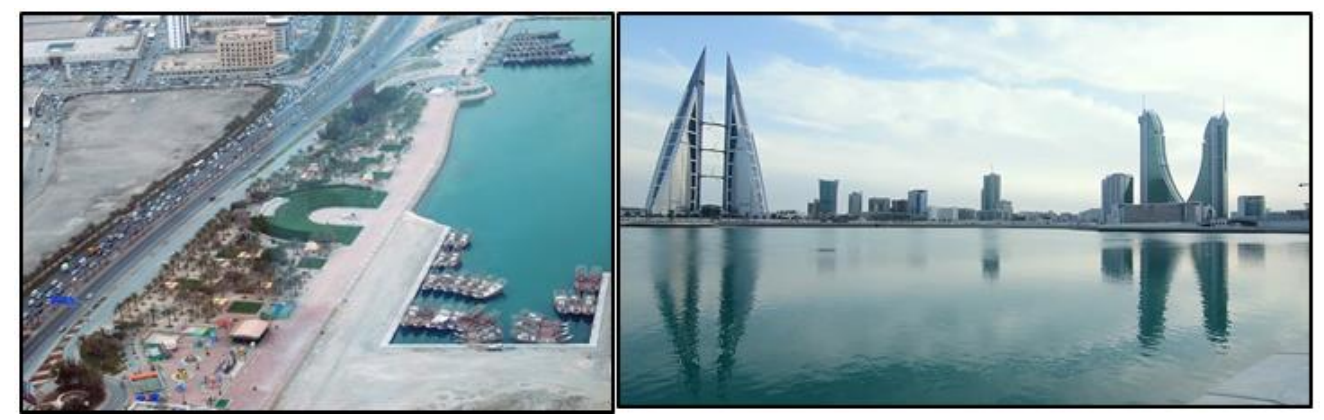

Fig-14: King Faisal Corniche. Source: wegenforum.nl. Figure 15: BFH and WTC. Source: shutterstock

Figure 16 below shows the surrounding landmarks in relation to the main two locations.

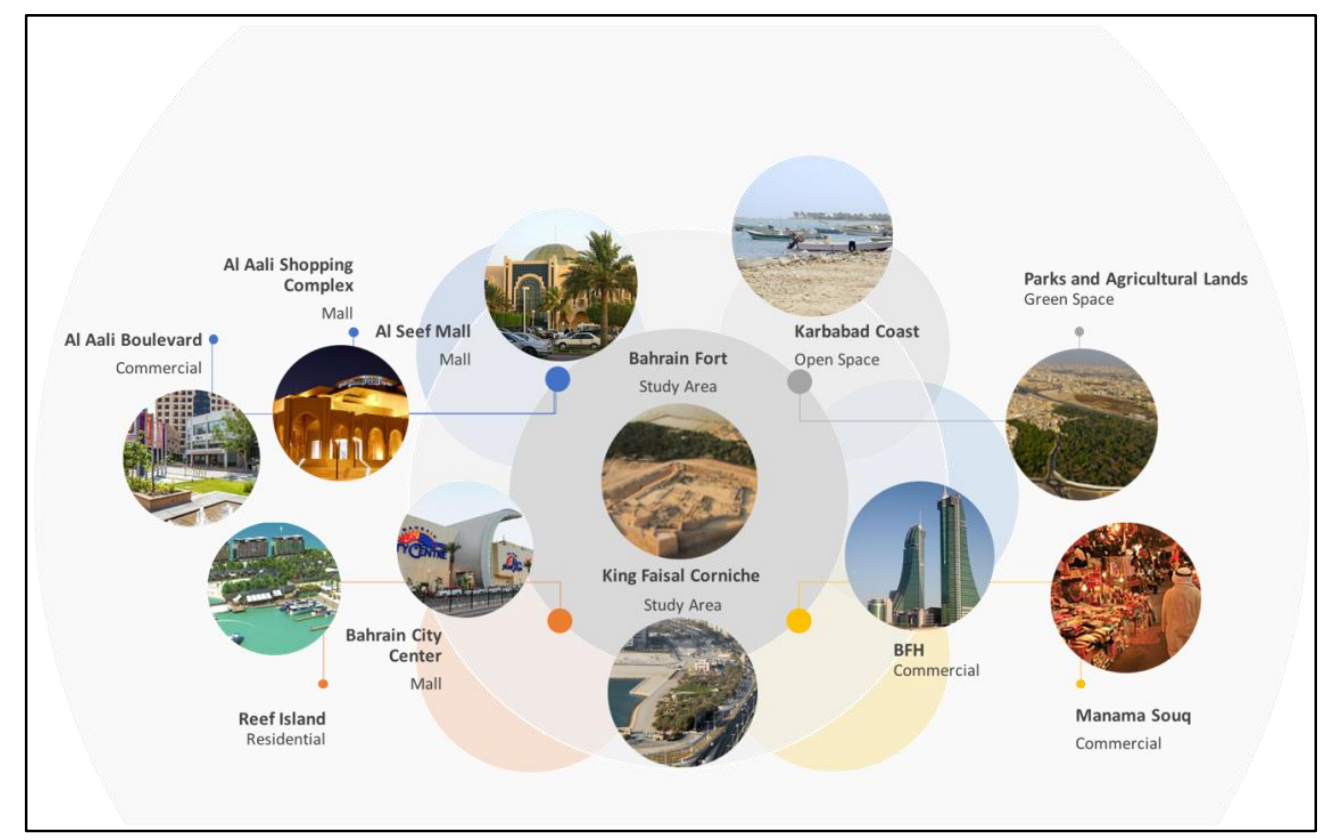

Fig-16: Surrounding landmarks. Source: Authors

\section{DISCUSSION}

All of these sites spread horizontally, starting with Bahrain Fort and moving to King Faisal Corniche. They are all not connected and perform individually; however, they are considered as crucial assets to the study area. Also, the findings indicated that the accessibility to these spots is mainly through the use of cars and few bus stops.

Because all of these sites are major points of attraction and are always crowded with people, there is a need to link them. This connectivity will result in a more vibrant city center that will draw different types of users and encourage them to walk, use bicycles or take public transportation to reach to their destination. In addition, more population means more business opportunities which will increase the land prices on a long-term basis.

Currently, the first phase of the seafront project plan, approved by the Supreme Committee for Urban Planning and under the chairmanship of His Highness the Crown Prince Shaikh Salman Bin Hamad Al Khalifa, is targeting the connection of major landmarks. The connection will start at Juffair and reach to King Faisal Corniche, and extending up to 14 
kilometres (Figure 17). This project is important to the study, as there is a future opportunity to seeing the linkage of Bahrain Fort and King Faisal Corniche as phase two of the seafront project.

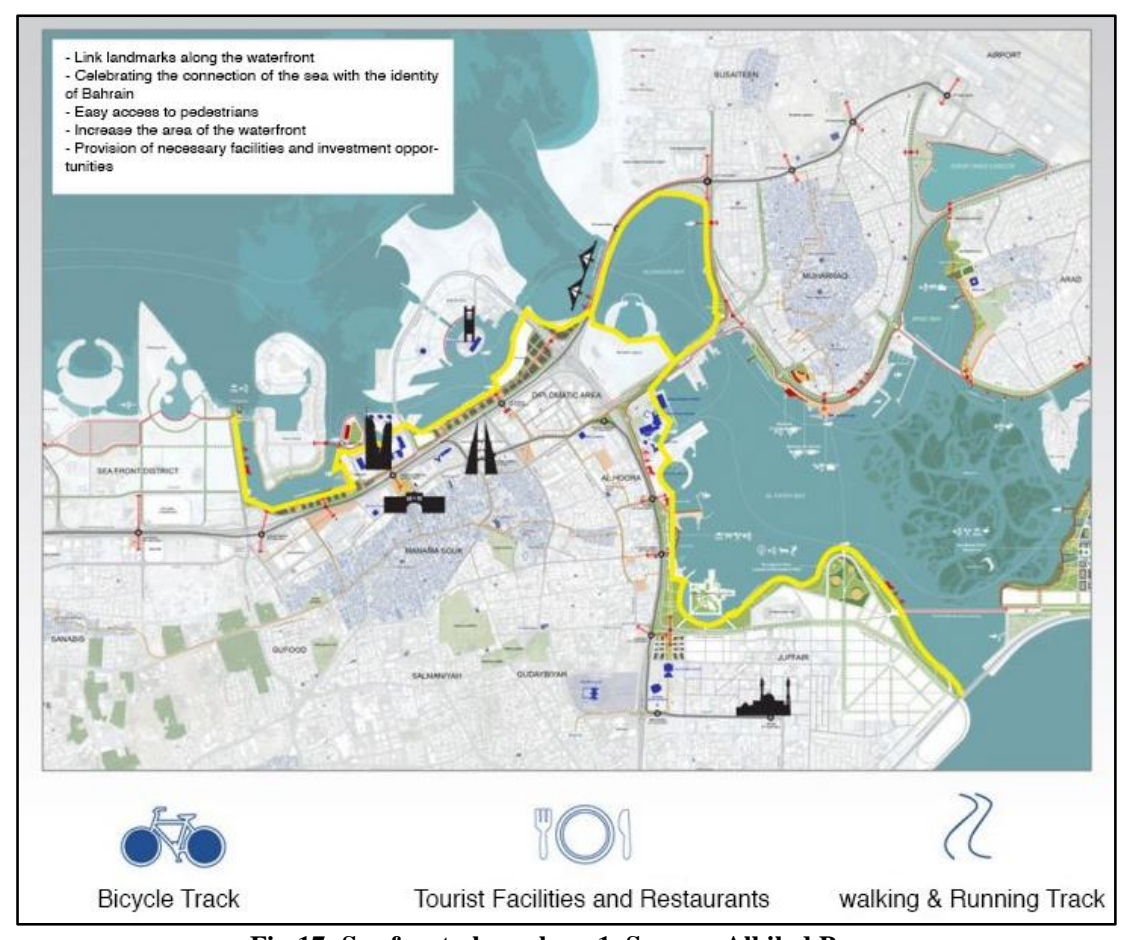

Fig-17: Sea front plan, phase 1. Source: Albilad Press

Adopting the same strategies and theme of the seafront project to the study is a must. To start with, Bahrain Fort and its museum need to be connected with Al Nakheel Road and Karbabad coast. This can be done through transforming Avenue 44, Qal'at al Bahrain Avenue, and Karbabad Avenue, into pedestrian walkways with bicycle lanes and adding safe crossings from Al-Nakheel Road (Figure 18). This will link the fort with residential areas and green areas around it. Karbabad coast need to be developed with the addition of public amenities.

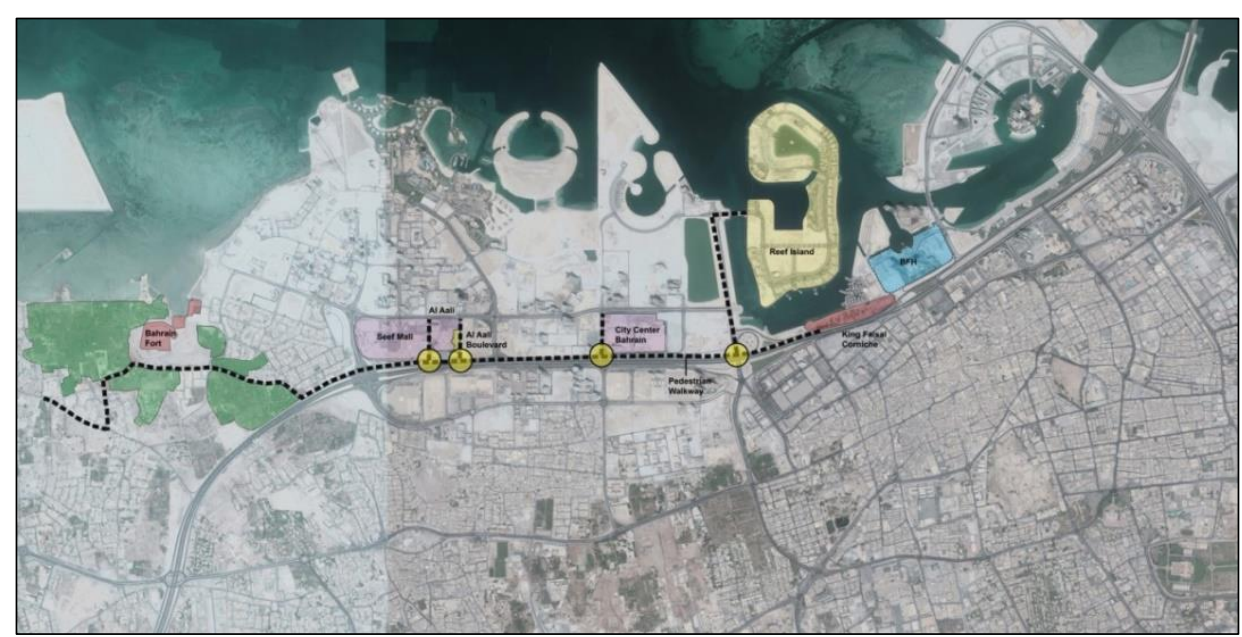

Fig-18: Map of the design proposal. Source: Authors

Moving from this place to the mall areas, a linkage can be established through Karbabad Avenue, creating a safe pedestrian walkway along Shaikh Khalifa Bin Salman Highway and King Faisal Highway. An elevated pedestrian bridge can connect Karbabad Avenue with the opposite area along Seef Mall and moving towards Al Aali shopping complex. From this point, the walkway should have a secondary access to Al Aali Boulevard into the cafés and restaurants.

The walkways can extend to reach City Center Bahrain all the way to King Faisal Corniche. A crossing node can be created to reach Reef Island and Water Garden City. The bridge reaching these developments can include a pedestrian walkway and bicycle path. 
Also, because Reef Island is overlooking the corniche, connecting it through water using traditional Bahraini ships will add an interesting mode of transportation and enhance the walking experience. The walkway can be fully pedestrianized with a unified patterned and shading. It can include commercial areas along it for an interesting experience. Eventually, this will enrich the area and attract businesses and increase land values. In addition to these walkways, public amenities can be incorporated in all these sites, such as sitting areas, trash bins, lighting poles, public toilets. The diagram below shows a summary of the Bahrain Fort and King Faisal Corniche design proposal.

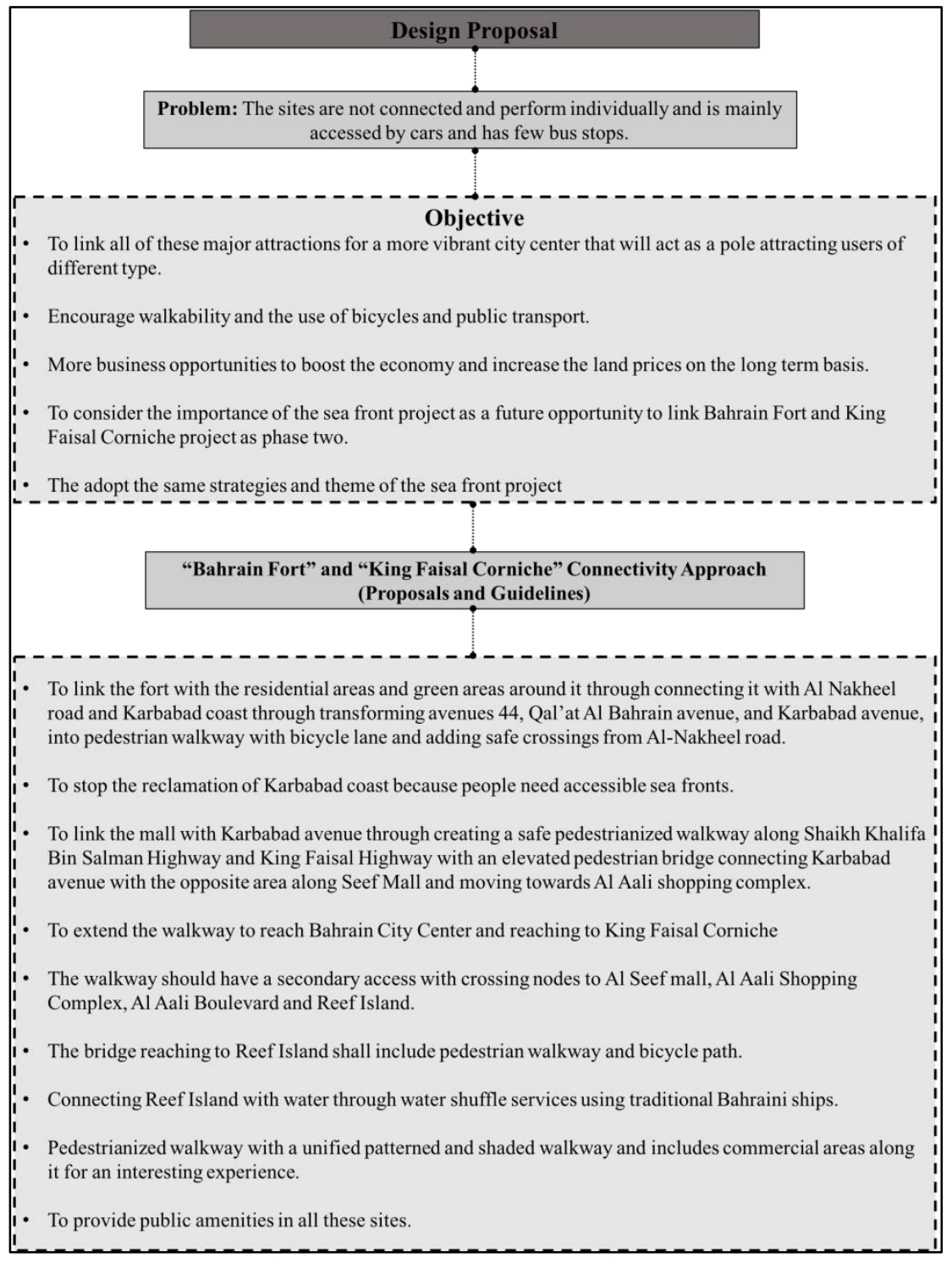

Fig-19: Summary of the design proposal. Source: Authors

\section{CONCLUSIONS}

With the growing consumption and population growth which has led to environmental degradation, cities and especially those in the Gulf region, urgently need to have open green spaces to reduce their ecological footprints and improve the quality of life. This research study has been focusing on the importance of open green public areas in Bahrain and the need to have them for social, economic, and environmental reasons. The study focuses on the Bahrain Fort and King Faisal Corniche as the main study area. Relevant literature review has been discussed to provide the concepts and the principles of green urbanism and public open spaces, in addition to their types, roles and effects in the city. The study further discussed the condition of parks and open spaces in Bahrain and specifically in Manama city which concluded with the low availability of those parks and open spaces.

The findings showed the great opportunities for the sites as well as the issues and problems, which led to ideas about how to design strategies to enhance these locations. The main strategy was to connect these landmarks with a pedestrianized walkway extending from Bahrain Fort and reaching to King Faisal 
Corniche. The project also adds crossing nodes to main landmarks to improve connectivity to these areas and boost the economy. The strategy adopted the same theme for the seafront project for future consideration that could be constructed as a second phase. The importance of this project is in line with the Bahrain National Vision 2030. The vision emphasizes the need to have a diversified economy and open public spaces for further improvement of the country.

\section{Implications for practice and advancement of research}

This study is significant because of the current effects of globalization, and the need to have open and connected public spaces with walkable streets to reduce the high usage of automobiles within the built environment. Also, this study can be adopted in different areas in Bahrain and in the Gulf Region where there is a need to embrace a similar approach. Due to the limitation of time, further aspects related to the site and its accessibility, park safety, and traffic calming strategies might be considered in future investigations.

\section{ACKNOWLEDGEMENTS}

Fatima Shubbar holds a bachelor's degree in Architecture from the University of Bahrain (Kingdom of Bahrain), and currently, she is undertaking a master's degree in Urban Design and Planning at Qatar University. She has 5 years of work experience as an architect.

Raffaello Furlan holds bachelor's and master's degrees from IUAV University in Venice (Italy), and a $\mathrm{PhD}$ in Architecture from Griffith University in Brisbane (Australia). He has held visiting and permanent positions in Australia (University of Queensland and Griffith University in Brisbane), UAE (Canadian University of Dubai), and Qatar (Qatar University). He has taught Art History, History of Architecture, Project Management, Urban Design, Architecture Design, and Interior Design. His areas of interest include Vernacular Architecture, Architecture and Urban Sociology, Project management, and Art History. A member of the Board of Architects in Italy and Australia, he has 20 years of professional experience, divided between design management, project management and supervision roles. These were with some highly respected companies, 6 years of which were in Italy, 10 years in Australia, and 4 years in the Middle East.

This research study was developed as an assignment at the core-course 'Sustainable Urban and Landscape Design' (MUPD710, Fall-2018) taught by Dr. Raffaello Furlan at Qatar University, College of Engineering, Department of Architecture and Urban Planning (DAUP), for the Master in Urban Planning and Design Program (MUPD).
The authors would like to express their gratitude to the leading planners and architects of Qatar's government agencies and ministries, namely the Ministry of Municipality and Environment (MME), Qatar Rail, Qatar Museum Authority, Ashgal Public Works Authority, and Qatar Rail for their collaboration, for participating in the meetings, sharing visual data and cardinal documents relevant to the research aims, and for discussing the results and conclusion of this investigation. Finally, the authors thank the anonymous reviewers for their comments, which contributed to an improvement of this paper. The authors are solely responsible for the statements made herein.

\section{REFERENCES}

1. Fox, J. W., Mourtada-Sabbah, N., \& al-Mutawa, M. (2006). Globalization and the Gulf. London, united Kingdom: Routledge.

2. Furlan, R., \& ElGihani, H. (2018). Post 2022 FIFA World Cup in the State Qatar: Urban Regeneration Strategies for Doha'. Journal of Urban Regeneration and Renewal, 11(4), 355-370.

3. Furlan, R., \& Sipe, N. (2017). Light Rail Transit (LRT) and Transit Villages in Qatar: A PlanningStrategy to Revitalize the Built Environment of Doha. Journal of Urban Regeneration and Renewal, 10(4), 1-20.

4. Furlan, R., \& Petruccioli, A. (2016). Affordable Housing for Middle Income Expats in Qatar: Strategies for Implementing Livability and Urban Form. International Journal of Architectural Research-ArchNet-IJAR, 10(3), 138-151.

5. Furlan, R., Zaina, S., \& Zaina, S. (2016). Urban Planning in Qatar: Strategies and Vision for the Development of Transit Villages in Doha. Australian Planner, 53(4), 286-301.

6. Al-Nabi, M. N. (2012). The History of Land use and Development in Bahrain. Bahrain: Information Affairs Authority.

7. UNESCO. (2005). Qal'at al-Bahrain - Ancient Harbour and Capital of Dilmun. Retrieved from http://whc.unesco.org

8. Beatley, T. (2000). Green Urbanism: Learning from European Cities. Washington, D.C., United States: Island Press.

9. Furlan, R., \& Almohannadi, M. (2016). Light Rail Transit and Land Use: An Integrated Planning Strategy for Al-Qassar's TOD in Qatar. International Journal of Architectural ResearchArchNet-IJAR, 10(3), 170-192.

10. Furlan, R., \& Saeed, M. A. (2019). TransitOriented Development in West Bay, Business District of Doha, State of Qatar: A Strategy for Enhancing Liveability and Sense of Place. Journal of Cultural Heritage Management and Sustainable Development, https://doi.org/10.1108/JCHMSD09-2018-0062.

11. Adhya, A., Plowright, P., \& Stevens, J. (2014). Defining Sustainable Urbanism: towards a responsive urban design. Paper presented at the 
Conference On Technology \& Sustainability in the Built Environment, King Saud University - College of Architecture and Planning.

12. Skrydstrup, M. (2016). Sustainable Development: An Appraisal from the Gulf Region. Paul Sillitoe, ed. New York: Berghahn, 2014. 556 pp. American Ethnologist, 43(2), 379-380.

13. Wiedmann, F., Salama, A., \& Mirincheva, V. (2014). Sustainable urban qualities in the emerging city of Doha. Journal of Urbanism: International Research on Placemaking and Urban Sustainability, 7(1), 62.84. Retrieved from http://dx.doi.org/10.1080/17549175.2013.870088.

14. Furlan, R., \& Mogra, S. (2017). Public Realm at Qatar University Campus: Perception and sustainability of Open Green Spaces. Saudi Journal of Humanities and Social Sciences, 2(1), 80-94.

15. Stepan, K. (2014). Green Space Perception.

16. Zhou, X., \& Rana, M. M. P. (2012). Social benefits of urban green space: A conceptual framework of valuation and accessibility measurements. Management of Environmental Quality: An International Journal, 23, 173-189.

17. Assali , I. M. (2015). Augmenting Urban Parks in Bahrain for the Improvement of Citizen's Health International Journal of Research in Engineering and Technology, 04(11), 140-152.

18. Burgess, J., Harrison, C. M., \& Limb, M. (1988). People, Parks and the Urban Green: A Study of Popular Meanings and Values for Open Spaces in the City. Urban Studies, 25, 455-473.

19. Chang, H.-S., \& Liao, C.-H. (2011). Exploring an integrated method for measuring the relative spatial equity in public facilities in the context of urban parks. Cities, 28(5), 361-371.

20. Nassar, U. (2000). Landscape as a tool to enhance behavioral response and activities in historic urban parks. Suez Canal University, Egypt.

21. Maulan, S. (2002). Seremban urban park, Malaysia. (Master's in Landscape Architecture). Virginia Polytechnic Institute \& State University,

22. Furlan, R., AlMohannadi, M., Zaina, S., \& Zaina, S. (2015). Integrated Approach for the Improvement of Human Comfort in the Public Realm: The Case of the Corniche, the Linear Urban Link of Doha. American Journal of Sociological Research, 89100.

23. Furlan, R., \& Alsuwaidi, M. (2017a). Katara Cultural Village in Qatar: Public Art and Urban Space. Journal of Arts and Humanities, 1(7), 559566.

24. Furlan, R., \& Alsuwaidi, M. (2017b). The Role of Public Art And Culture in New Urban Environments: The Case of 'Katara Cultural Village' In Qatar. Architecture Research, 7(3).

25. Furlan, R., Muneerudeen, A., \& Khani, F. A. (2016). Urban Revitalization of Public Spaces in the Pearl in Qatar. American Journal of Sociological Research, 6(1), 1-9.

26. Furlan, R., \& Shurbaji, M. (2017). The Sheraton Park and Users' Human Behaviour: Strategies for Implementation of the Public Realm in Doha. American Journal of Sociological Research, 7(1).

27. Furlan, R., Petruccioli, A., \& Jamaleddin, M. (2019). The authenticity of place-making: space and character of the regenerated historic district in Msheireb, Downtown Doha (State of Qatar). International Journal of Architectural ResearchArchNet-IJAR, 13(1), 151*168.

28. Furlan, R., Petruccioli, A., Major, M., Zaina, S., Saeed, M. A., \& Saleh, D. (2018). The Urban Regeneration of West-Bay, Business District of Doha (State of Qatar): A Transit Oriented Development Enhancing Livability. Journal of Urban Management, 8(1), 126-144.

29. Furlan, R., \& Alattar, D. (2017). Urban Regeneration in Qatar: A Comprehensive Planning Strategy for the Transport Oriented Development (TOD) of Al-Waab. Journal of Urban Regeneration and Renewal, 11(2), 168-193.

30. McCormack, G., Rock, M., Toohey, A., \& Hignell, D. (2010). Characteristics of urban parks associated with park use and physical activity. Health and Place, 16(04), 712-726.

31. Healthy Spaces \& Places. (2009). Design Principle - Connectivity and Permeability. Retrieved from www.healthyplaces.org.au

32. Ioja, C. I., Gradinaru, S. R., Onose, D. A., Vanau, G. O., \& Tudor, A. C. (2014). The potential of school green areas to improve urban green connectivity and multifunctionality. Urban Forestry \& Urban Greening, 13(04), 704-713.

33. Elsheshtawy, Y. (2008). The Evolving Arab City: Tradition, Modernity \& Urban Development. Oxfordshire, United Kingdom: Routledge.

34. Information and eGovernment Authority. (2015). Bahrain Open Data Portal. Retrieved from http://www.data.gov.bh

35. Planning, G. D. o. U. (2008). Bahrain National Strategic Plan 2030: Bahrain National Plan. Retrieved from

36. Board, B. E. D. (2017). National Development Strategy. Retrieved from http://bahrainedb.com/about-us/nationaldevelopment-strategy/

37. Creswell, J. (1994). Research Design: Qualitative and Quantitative Approaches. Thousand Oaks, California: Sage Publications.

38. Denzin, N. K., \& Lincoln, Y. S. (2005). The Sage Handbook of Qualitative Research. London: Sage Publications.

39. Marshall, C., \& Rossman, G. B. (2010). Designing Qualitative Research (3 ed.). California: Sage Publication. 